\title{
BALANÇO DA PRODUÇÃO CIENTÍFICA DO PROFEPT SOBRE EVASÃO ESCOLAR
}

Rogério Costa Batista ${ }^{1}$, Sandro Rodrigues de Oliveira ${ }^{2}$, Ed Wilson Tavares Ferreira $^{3}$, Vanderley Severino dos Santos ${ }^{4}$, Geison Jader Mello ${ }^{5}$

1 Mestrando do Programa de Mestrado Profissional em Educação Profissional e Tecnológica (ProfEPT), IFMT Campus Cuiabá (rogeriocostab@hotmail.com)

2 Mestrando do Programa de mestrado Profissional em Educação Profissional e Tecnológica (ProfEPT), IFMT Campus Cuiabá

3 Professor Doutor no Programa de Mestrado Profissional em Educação Profissional e Tecnológica (ProfEPT), IFMT Campus Cuiabá

4 Professor Doutor no Programa de Mestrado Profissional em Educação Profissional e Tecnológica (ProfEPT), IFMT Campus Cuiabá

5 Professor Doutor no Programa de Mestrado Profissional em Educação Profissional e Tecnológica (ProfEPT), IFMT Campus Cuiabá

Recebido em: 15/11/2021 - Aprovado em: 15/12/2021 - Publicado em: 30/12/2021

DOI: 10.18677/EnciBio_2021D10

trabalho licenciado sob licença Creative Commons Attribution-NonCommercial-NoDerivatives 4.0 International License.

\section{RESUMO}

A evasão escolar é um sério problema que atinge as instituições acadêmicas em todo o Brasil. As pesquisas desenvolvidas demonstram que diversos fatores contribuem de forma significativa para que o estudante corte o vínculo com a escola. O acesso à educação é um dever do estado e da família, conforme prevê a Constituição Federal. Neste artigo, de revisão bibliográfica, os autores investigaram as publicações de dissertações defendidas no Programa de Mestrado Profissional em Educação Profissional e Tecnológica (ProfEPT) cujas pesquisas foram relacionadas à evasão escolar. Foi possível identificar os principais autores que balizaram as pesquisas dos alunos do programa de mestrado e os respectivos produtos educacionais, desenvolvidos e aplicados em instituições de ensino. Neste percurso metodológico foi empregada a consulta ao Observatório ProfEPT. Os resultados obtidos permitiram identificar ações realizadas nas instituições para mitigar a evasão escolar. A análise das pesquisas relatadas contribuiu para aprimorar o entendimento acerca do tema analisado.

PALAVRAS-CHAVE: Direito à educação. Práticas escolares. Sucesso e fracasso escolar.

\section{BALANCE OF PROFEPT'S SCIENTIFIC PRODUCTION ON STUDENT'S DROPOUT}

\section{ABSTRACT}

Dropping out of school is a serious problem that affects academic institutions throughout Brazil. The research carried out demonstrates that several factors contribute significantly to the student's break with the school. Access to education is 
a duty of the state and the family, as provided for in the Federal Constitution. In this article, a bibliographical review, the authors investigated the publications of dissertations defended in the Professional Master's Program in Professional and Technological Education (ProfEPT) whose research was related to school dropout. It was possible to identify the main authors that guided the research of the master's program students and the respective educational products, developed and applied in educational institutions. In this methodological path, the consultation of the ProfEPT Observatory was used. The results obtained made it possible to identify actions taken in institutions to mitigate school dropout rates. The analysis of the researches reported contributed to improve the understanding of the analyzed theme.

KEYWORDS: Right to education. School practices. School success and failure.

\section{INTRODUÇÃO}

As instituições escolares arrostam dificuldades para desenvolver atividades intrínsecas à sua natureza. Uma parte considerável das escolas enfrentam desafios que permeiam aspectos relacionados à infraestrutura física, quantidade insuficiente de profissionais da educação, e ainda, fragilidades quanto às condições socioeconômicas dos estudantes (SILVA, 2020).

Para um significativo grupo de instituições, o reflexo deste cenário é a evasão escolar, que é caracterizada pela quebra do vínculo do estudante com a escola, situação que ocorre quando ele deixa de frequentar as aulas (COSTA, 2018).

De outro lado, a permanência e êxito, ocorre quando o estudante cumpre os requisitos acadêmicos e logra êxito em sua formação. Carmo (2018) cita a importância da temática de permanência e êxito dos estudantes, pois está relacionada à uma dimensão social da qualidade na educação e, além disso, é um meio de avaliar o cumprimento da função das instituições escolares.

O fenômeno da evasão escolar deve ser colocado no topo das pautas educacionais, uma vez que "a negação da escolarização não significa a exclusão do acesso dos jovens à escola, mas uma exclusão que, no seu próprio interior, promove a perda da função social da escola de promover a formação dos seus educandos" (RAMOS, 2010, p. 98).

Ademais, Costa (2020) descreve a importância de aprofundar os conhecimentos sobre os programas de permanência e êxito existentes. De forma semelhante, Sousa (2020, p.17) completa que a motivação está relacionada ao serviço social, $[\ldots\}$ "onde teve que conviver com os constantes índices de evasão dos estudantes".

Para Garcia (2020), que atua na Coordenadoria Pedagógica, a motivação para pesquisar encontra-se no regimento interno da instituição, que reza sobre o acolhimento dos alunos e sua permanência na instituição. Diversos aspectos contribuem para a evasão escolar, e Shcargel e Smink (2002) destacam os achados psicológicos, sociológicos, organizacionais, além dos econômicos, que influenciam o aluno a abandonar os estudos.

A evasão escolar assola os dois níveis de ensino brasileiro: básico e superior. A educação básica é formada pelo ensino fundamental e ensino médio, inclusive os cursos técnicos. A educação superior é composta pelos cursos de graduação (bacharelado, licenciatura e tecnólogo) e pós-graduação (mestrado e doutorado) (BRASIL, 2017). 
A Rede Federal de Educação Profissional e Tecnológica (RFEPT $\left.{ }^{1}\right)$ é composta pelos Centros Federais de Educação Tecnológica Celso Suckow da Fonseca do Rio de Janeiro (Cefet-RJ) e de Minas Gerais (Cefet-MG), pelas Escolas Técnicas vinculadas às Universidades Federais e Colégio Pedro II, pela Universidade Tecnológica Federal do Paraná - UTFPR, e pelos Institutos Federais de Educação, Ciência e Tecnologia (Institutos Federais - IFs). Esta rede oferta Educação Básica, Técnica e Tecnológica - EBTT, além de pós-graduação. É centrada nos princípios basilares da integração entre ensino, pesquisa e extensão. A RFEPT é responsável pelo Programa de Pós-Graduação em Educação Profissional e Tecnológica - ProfEPT ${ }^{2}$, que oferta o Mestrado Profissional em Educação Profissional, no formato em rede, com a participação das instituições presentes no distrito federal e em todas as unidades da federação brasileira.

Em 2013 o Tribunal de Contas da União (TCU) publicou o Acórdão oㅜ 506 ${ }^{3}$, que determinou a fiscalização centralizada sobre ações de combate à evasão na RFEPT, o mesmo documento indicou a necessidade de aprimoramentos das atuações da rede e sua interligação com os arranjos produtivos locais. A atuação do órgão de controle externo do poder executivo, que é responsável pelo acompanhamento da execução orçamentária e financeira das instituições públicas federais, confirma a importância da mitigação à evasão escolar (BRASIL, 2013)

A partir deste evento, ações existentes de combate à evasão da RFEPT foram publicadas e novas atuações foram implementadas. Além dos aspectos administrativos e pedagógicos, diversas pesquisas foram desenvolvidas com o objetivo de avaliar, propor e implementar medidas para mitigar a evasão (ANDRADE, et al., 2021).

O objetivo geral neste artigo foi a investigação das publicações de dissertações, no âmbito do ProfEPT, acerca de pesquisas sobre evasão escolar. Foi possível identificar os principais aportes teóricos utilizados, os produtos educacionais desenvolvidos e aplicados pelos recém mestres, além das principais contribuições dos estudos.

\section{MATERIAL E METODOS}

Está é uma pesquisa com abordagem qualitativa, De acordo com Taquette e Borges (2020), o principal tipo de dado da pesquisa qualitativa é textual, advindo da observação, das entrevistas, de documentos, notas de campo e bibliografias, podem ser também imagens e fotografias.

Os autores realizaram a revisão bibliográfica de 20 dissertações publicadas no período de 2018 a 2021, no programa de mestrado ProfEPT e foi analisada a relação entre as obras selecionadas. Conforme Marconi e Lakatos (2017, p. 26) explicam: esta análise "tem como objetivo encontrar as principais relações, em estabelecer conexões com os diferentes elementos constitutivos do texto".

O Observatório ProfEPT ${ }^{4}$ é um sistema de acompanhamento de pesquisa e publicações do programa de mestrado em rede, foi desenvolvido pelo Grupo de Pesquisa em Mineração de Dados e Imagens (MiDI) do Instituto Federal do Triângulo Mineiro - IFTM, Campus Avançado Uberaba Parque Tecnológico.

\footnotetext{
1 http://portal.mec.gov.br/rede-federal-inicial/

2 https://profept.ifes.edu.br/

3 https://www.lexml.gov.br/urn/urn:lex:br:tribunal.contas.uniao;plenario:acordao:2013-03$13 ; 506$

4 https://obsprofept.midi.upt.iftm.edu.br/
} 
Observatório coleta dados de diferentes fontes: Plataforma Sucupira; Plataforma Lattes; dados informados pelos alunos, secretários e docentes do ProfEPT. O sistema permite realizar a consulta de dissertações publicadas, e nesta pesquisa, foi utilizada a palavra-chave (string de busca) "permanencia" para selecionar as dissertações publicadas.

O primeiro processo seletivo do ProfEPT ocorreu no ano de 2017, portanto, como esperado a primeira publicação de dissertação ocorreu após o ano de 2018. A listagem das dissertações obtidas acerca do tema pesquisado é apresentada e discutida na próxima seção, e a identificação completa foi inserida nas referências.

\section{RESULTADOS E DISCUSSÕES}

A pesquisa no sistema de busca no Observatório ProfEPT produziu a listagem composta por 20 dissertações relacionadas ao tema evasão, no âmbito do Programa de Mestrado Profissional em Educação Profissional e Tecnológica, (Quadro 1). Para cada dissertação obtida, foram elencados o título, autor, linha de pesquisa, problema de pesquisa, principais autores utilizados no aporte teórico da pesquisa, produto educacional, e finalmente, os resultados obtidos.

No programa ProfEPT, o mestrando deve desenvolver um produto educacional, categorizado de acordo com a Coordenação de Aperfeiçoamento de Pessoal de Nível Superior (CAPES), que deve ser aplicado na solução de um determinado problema, e que é validado pelos membros que compõem a banca de mestrado. Portanto, todos os produtos foram empregados em um cenário real para solucionar um problema real. 
QUADRO 1 - Categorização das dissertações defendidas no programa de mestrado ProfEPT durante o período de janeiro de 2019 a novembro de 2021

\begin{tabular}{|c|c|c|c|c|c|}
\hline Título / Autor & $\begin{array}{c}\text { Linha de } \\
\text { pesquisa / } \\
\text { Vínculo }\end{array}$ & $\begin{array}{c}\text { Problema de } \\
\text { Pesquisa }\end{array}$ & \begin{tabular}{|c|} 
Principais \\
autores \\
utilizados no \\
aporte teórico da \\
pesquisa
\end{tabular} & $\begin{array}{c}\text { Produto } \\
\text { Educacional }\end{array}$ & $\begin{array}{c}\text { Resultados informados pelo } \\
\text { autor no resumo da } \\
\text { dissertação }\end{array}$ \\
\hline $\begin{array}{l}\text { Educação } \\
\text { profissional e } \\
\text { tecnológica: } \\
\text { avaliação do ensino } \\
\text { como instrumento } \\
\text { de gestão para a } \\
\text { permanência } \\
\text { escolar } \\
\text { (COSTA, 2020) }\end{array}$ & $\begin{array}{l}\text { Gestão e } \\
\text { organizaçã } \\
\text { o do } \\
\text { espaço } \\
\text { pedagógico } \\
\text { em EPT - } \\
\text { Servidora } \\
\text { da } \\
\text { Instituição } \\
\text { (IFPE) }\end{array}$ & $\begin{array}{lr}\text { Quais os limites e } \\
\text { possibilidades da } \\
\text { avaliação do ensino, } \\
\text { enquanto instrumento } \\
\text { de gestão do } \\
\text { programa de acesso, } \\
\text { permanência e êxito } \\
\text { do IFPE, r para } \\
\text { promover } \\
\text { permanência r no } \\
\text { âmbito da EPT? }\end{array}$ & $\begin{array}{l}\text { Gleice Emerick de } \\
\text { Oliveira; } \\
\text { Heloísa Lück; } \\
\text { Juarina Ana da } \\
\text { Silveira Souza; } \\
\text { Renato César do } \\
\text { Carmo Canesso. }\end{array}$ & $\begin{array}{ll}\text { Formulário } & \text { de } \\
\text { avaliação } & \text { do } \\
\text { ensino } & \text { no } \\
\text { PROIFPE, } & \\
\text { apresentando } & \text { um } \\
\text { instrumento } & \text { de } \\
\text { avaliação } & \text { do } \\
\text { ensino } & \text { no } \\
\text { programa } & \text { de } \\
\text { acesso } & \\
\text { permanência } & \text { e } \\
\text { êxito do IFPE, } & \text { câmpus Recife. } \\
\end{array}$ & $\begin{array}{l}\text { A relação aluno-professor e a } \\
\text { atuação docente que decorre } \\
\text { do trabalho em equipe. } \\
\text { Enquanto como aspectos } \\
\text { fragilizados do Programa, } \\
\text { pode-se apontar, a ínfima } \\
\text { participação de docentes } \\
\text { efetivos e a infraestrutura de } \\
\text { sala de aula. }\end{array}$ \\
\hline
\end{tabular}




\begin{tabular}{|c|c|c|c|c|c|}
\hline $\begin{array}{l}\text { Atividades e ações } \\
\text { de extensão no } \\
\text { IFMS: interfaces } \\
\text { com a permanência } \\
\text { e êxito } \text { dos } \\
\text { estudantes }(S A ́, \\
2020)\end{array}$ & $\begin{array}{l}\text { Organizaçã } \\
\text { o e } \\
\text { memórias } \\
\text { de espaços } \\
\text { pedagógico } \\
\text { S na EPT - } \\
\text { Servidora } \\
\text { da } \\
\text { Instituição } \\
\text { (IFMS) }\end{array}$ & $\begin{array}{l}\text { O fenômeno da } \\
\text { evasão e retenção } \\
\text { apresentam } \\
\text { diversos níveis de } \\
\text { ensino, modalidades e } \\
\text { instituições, o que } \\
\text { ocorre na rede federal } \\
\text { de r educação } \\
\text { profissional, científica } \\
\text { e tecnológica e no } \\
\text { IFMS }\end{array}$ & $\begin{array}{l}\text { Dermeval Saviani } \\
\text { Gaudêncio } \\
\text { Frigotto; } \\
\text { Maria Ciavatta; } \\
\text { Marise Nogueira } \\
\text { Ramos; } \\
\text { Paulo Reglus } \\
\text { Neves Freire. }\end{array}$ & 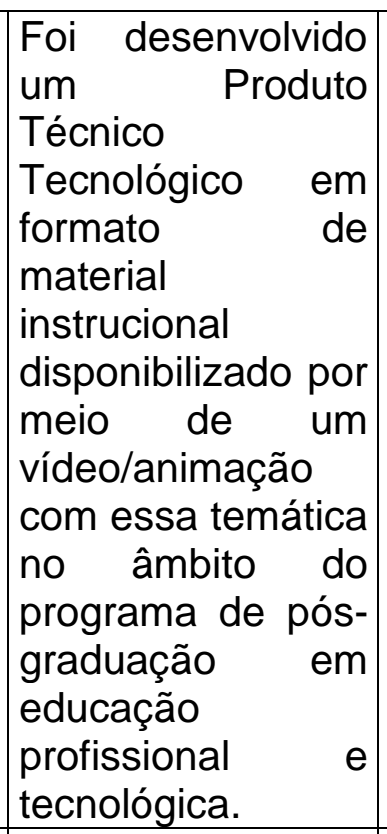 & $\begin{array}{l}\text { Foi possível identificar que os } \\
\text { estudantes, em grande parte, } \\
\text { já participaram de alguma } \\
\text { extensão. } \\
\text { desconhecimento sobre a } \\
\text { temática no percurso } \\
\text { formativo, } \\
\text { dificuldades que os levaram a } \\
\text { pensar em abandonar o curso } \\
\text { e fatores diversos envolvidos, } \\
\text { portanto, as estratégias devem } \\
\text { ser promovidas para superar } \\
\text { os índices de evasão e } \\
\text { retenção. }\end{array}$ \\
\hline \begin{tabular}{|lrr} 
Desafios & da \\
permanência & do \\
estudante- & \\
trabalhador & no & IF \\
Sudeste & MG- \\
campus & Barbacena: \\
\end{tabular} & $\begin{array}{l}\text { Organizaçã } \\
\text { o e } \\
\text { memórias } \\
\text { de espaços } \\
\text { pedagógico } \\
\text { s na EPT - }\end{array}$ & \begin{tabular}{lr} 
Como & \multicolumn{2}{c}{ compreender } \\
os fatores & que \\
influenciam r a & a \\
permanência & do \\
estudante-trabalhador & \multicolumn{2}{l}{ matriculado no curso }
\end{tabular} & $\begin{array}{l}\text { Acácia Zeneida } \\
\text { Kuenzer; } \\
\text { Dante Henrique } \\
\text { Moura; } \\
\text { Eliezer Pacheco; } \\
\text { Gaudêncio }\end{array}$ & 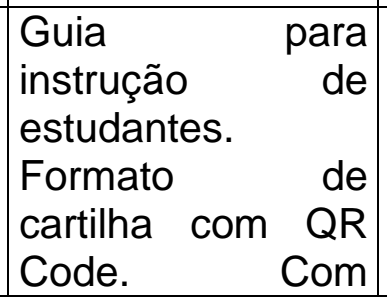 & $\begin{array}{l}\text { Os resultados revelaram que a } \\
\text { maioria desses estudantes } \\
\text { exercem profissões de baixo } \\
\text { status social equivalentes às } \\
\text { de seus pais, embora } \\
\text { possuam um nível de }\end{array}$ \\
\hline
\end{tabular}




\begin{tabular}{|c|c|c|c|c|c|}
\hline $\begin{array}{l}\text { um estudo de caso } \\
\text { nos cursos } \\
\text { subsequentes } \\
\text { (LUCENA, 2020) }\end{array}$ & $\begin{array}{l}\text { Servidora } \\
\text { Instituição- } \\
\text { IF Sudeste } \\
\text { MG }\end{array}$ & $\begin{array}{l}\text { da modalidade } \\
\text { subsequente do IF } \\
\text { Sudeste MG- campus } \\
\text { Barbacena }\end{array}$ & $\begin{array}{ll}\text { Frigotto: } & \\
\text { José } & \text { Carlos } \\
\text { Libâneo; } & \\
\text { Karina } & \text { Griggio } \\
\text { Hotz; } & \\
\text { Maria Ciavatta } \\
\text { Silvia } \quad \text { Maria } \\
\text { Manfredi. } & \end{array}$ & $\begin{array}{l}\text { informações sobre } \\
\text { os cursos técnicos } \\
\text { subsequentes, } \\
\text { políticas públicas, } \\
\text { práticas } \\
\text { pedagógicas, } \\
\text { serviços, } \\
\text { programas, } \\
\text { projetos } \\
\text { legislações } \\
\text { institucionais, } \\
\text { permitindo que } \\
\text { esses estudantes } \\
\text { se mantenham, } \\
\text { promovendo, } \\
\text { assim, } \\
\text { engajamento } \\
\text { institucional } \\
\text { discente. }\end{array}$ & $\begin{array}{l}\text { escolaridade maior, sendo a } \\
\text { permanência nos cursos } \\
\text { subsequentes motivada } \\
\text { principalmente por fatores que } \\
\text { compõem o contexto escolar, } \\
\text { como as práticas pedagógicas } \\
\text { e as políticas públicas de } \\
\text { permanência. Soma-se a isso } \\
\text { as perspectivas positivas de } \\
\text { melhoria profissional e } \\
\text { verticalização educacional. }\end{array}$ \\
\hline
\end{tabular}




\begin{tabular}{|c|c|c|c|c|c|}
\hline $\begin{array}{lr}\text { Evasão } & e \\
\text { reprovação } & \text { no } \\
\text { ensino } & \text { médio } \\
\text { integrado r } & \text { do } \\
\text { CEFET-MG } & \text { campus } \\
\text { Leopoldina: } & \text { uma } \\
\text { proposta de manual } & \text { mara a comissão de } \\
\text { permanência e êxito } \\
\text { perman } \\
\text { (BARBOSA, 2019) }\end{array}$ & $\begin{array}{l}\text { Práticas } \\
\text { educativas } \\
\text { em EPT } \\
\text { Servidor } \\
\text { Público } \\
\text { (CEFET } \\
\text { MG). }\end{array}$ & $\begin{array}{l}\text { Como reduzir os } \\
\text { índices de evasão e } \\
\text { reprovação no Ensino } \\
\text { Médio Integrado ao } \\
\text { Ensino Profissional do } \\
\text { CEFET-MG, campus } \\
\text { Leopoldina, } \\
\text { especialmente nas } \\
\text { turmas de } 1^{\circ} \text { ano? }\end{array}$ & $\begin{array}{l}\text { Bernard Charlot; } \\
\text { Dermeval Saviani } \\
\text { Gaudêncio } \\
\text { Frigotto: } \\
\text { Lilá Reis Lopes; } \\
\text { Maria Ciavatta; } \\
\text { Marise Nogueira } \\
\text { Ramos. }\end{array}$ & $\begin{array}{l}\text { Manual } \\
\text { comissão } \\
\text { permanência } \\
\text { êxito. }\end{array}$ & $\begin{array}{l}\text { A partir da pesquisa } \\
\text { empreendida, foi possível } \\
\text { compreender algumas causas } \\
\text { da evasão e reprovação na } \\
\text { instituição, como falta de apoio } \\
\text { da escola, de base } \\
\text { educacional e de motivação } \\
\text { para os estudos, utilização de } \\
\text { redes sociais e jogos, carga } \\
\text { horária elevada e sobrecarga } \\
\text { de atividades. }\end{array}$ \\
\hline $\begin{array}{lr}\text { Conhecendo } & 0 \\
\text { curso técnico } & \text { em } \\
\text { metalurgia do } & \text { IFMG } \\
-\quad \text { campus } & \text { Ouro } \\
\text { Preto: reconstrução } \\
\text { histórica do } & \text { curso } \\
\text { comor } & \text { ação } \\
\text { motivacional } & \text { para } \\
\text { permanência e êxito } \\
\text { discente (VICENTE, } \\
\text { 2019). }\end{array}$ & $\begin{array}{l}\text { Organizaçã } \\
\text { o e } \\
\text { memórias } \\
\text { de espaços } \\
\text { pedagógico } \\
\text { s na EPT - } \\
\text { Servidora } \\
\text { Pública } \\
\text { (IFMG) }\end{array}$ & $\begin{array}{l}\text { Como resgatar a } \\
\text { importância histórica } \\
\text { do curso técnico em } \\
\text { metalurgia do IFMG - } \\
\text { campus Ouro Preto e } \\
\text { o protagonismo de } \\
\text { seus alunos e } \\
\text { professores, na forma } \\
\text { de um memorial, } \\
\text { como ação } \\
\text { motivacional que } \\
\text { contribua para a } \\
\text { permanência e êxito } \\
\text { discente. }\end{array}$ & $\begin{array}{ll}\text { Arthur } & \text { Versiani } \\
\text { Machado; } & \\
\text { Dante Henrique } & \\
\text { Moura; } & \\
\text { Gaudêncio } & \\
\text { Frigotto; } & \\
\text { João Bosco Rio; } & \\
\text { Josér } \quad \text { Carlos } \\
\text { Libâneo; } \\
\text { Josér Murilo } \\
\text { Carvalho; } \\
\text { Maria Ciavatta; } \\
\text { Marise Nogueira } \\
\text { Ramos. }\end{array}$ & $\begin{array}{lr}\text { O memorial do } \\
\text { CTM do IFMG - } \\
\text { câmpus r Ouro } \\
\text { Preto } & \text { foi } \\
\text { construído } & \text { na } \\
\text { forma de um } & \text { blog } \\
\text { usando } & \text { a } \\
\text { ferramenta } & \\
\text { WordPress } & 19 .\end{array}$ & $\begin{array}{l}\text { A reconstrução histórica do } \\
\text { Curso Técnico em Metalurgia } \\
\text { por meio do memorial, } \\
\text { fomentou a apropriação da } \\
\text { história do curso pelos alunos } \\
\text { contribuindo para com } \\
\text { sentimentos de pertencimento } \\
\text { e protagonismo, resultando na } \\
\text { permanência e êxito destes no } \\
\text { curso. }\end{array}$ \\
\hline \begin{tabular}{|lrr} 
A eficiência & da \\
monitoria & nos \\
cursos & técnicos \\
integrados & ao \\
ensino & médio & do \\
instituto & federal \\
Goiano & - & campus
\end{tabular} & $\begin{array}{l}\text { Organizaçã } \\
\text { o e } \\
\text { Memórias } \\
\text { de Espaços } \\
\text { Pedagógico } \\
\text { s na EPT - } \\
\text { Servidora }\end{array}$ & $\begin{array}{l}\text { Qual é a importância } \\
\text { da do programa de } \\
\text { monitoria no processo } \\
\text { de ensino- } \\
\text { aprendizagem, } \\
\text { influenciando na } \\
\text { permanência e no }\end{array}$ & $\begin{array}{l}\text { Acácia Kuenzer; } \\
\text { Dante Henrique } \\
\text { Moura; } \\
\text { Dermeval Saviani; } \\
\text { Eliezer Pacheco; } \\
\text { Gaudêncio } \\
\text { Frigotto: }\end{array}$ & $\begin{array}{lr}\text { História } & \text { em } \\
\text { quadrinhos } & (\mathrm{HQ}) \\
\text { "A importância da } \\
\text { monitoria" }\end{array}$ & $\begin{array}{l}\text { Verificou-se que a } \\
\text { monitoração, no IF Goiano } \\
\text { contribui para mudanças } \\
\text { perceptíveis na aprendizagem, } \\
\text { ajudando a minimizar a } \\
\text { defasagem de conteúdos e } \\
\text { refletindo de forma positiva na }\end{array}$ \\
\hline
\end{tabular}




\begin{tabular}{|c|c|c|c|c|c|}
\hline 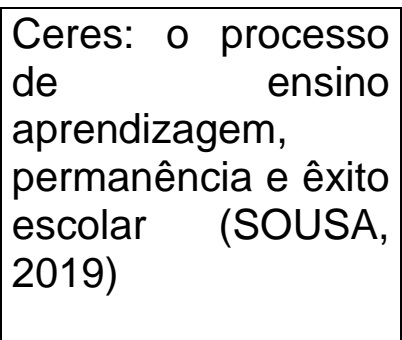 & $\begin{array}{l}\text { Pública } \\
\text { (IFG) }\end{array}$ & $\begin{array}{l}\text { êxito escolar dos } \\
\text { estudantes? }\end{array}$ & $\begin{array}{lr}\text { Luís } & \text { Antônio } \\
\text { Cunha; } & \\
\text { Maria Ciavatta: } & \\
\text { Maria } & \text { Helena } \\
\text { Câmara } & \text { Bastos; } \\
\text { Silvia } & \text { Maria } \\
\text { Manfredi. } & \end{array}$ & & $\begin{array}{l}\text { permanência e no êxito } \\
\text { escolar. }\end{array}$ \\
\hline $\begin{array}{lr}\text { Guia educacional } \\
\text { sobre os fatores de } \\
\text { permanência e êxito } \\
\text { dos } & \text { alunos } \\
\text { egressos da rede } \\
\text { pública do ensino } \\
\text { fundamental } & \text { no } \\
\text { ensino } & \text { médio } \\
\text { integrado do IFSC- } \\
\text { câmpus r r } \\
\text { Florianópolis } \\
\text { (RIBEIRO, 2020). }\end{array}$ & $\begin{array}{l}\text { Práticas } \\
\text { educativas } \\
\text { em EPT - } \\
\text { Servidora } \\
\text { Público- } \\
\text { Supervisora } \\
\text { Escolar da } \\
\text { Rede } \\
\text { Municipal }\end{array}$ & $\begin{array}{l}\text { Quais são as } \\
\text { condições } \\
\text { necessárias para o } \\
\text { enfrentamento dos } \\
\text { desafios encontrados } \\
\text { pelos egressos do } \\
\text { ensino fundamental } \\
\text { da rede pública para } \\
\text { permanecer e ter êxito } \\
\text { nos cursos de ensino } \\
\text { médio integrado do } \\
\text { IFSC - Campus } \\
\text { Florianópolis?" }\end{array}$ & $\begin{array}{l}\text { Adilson Cesar } \\
\text { Araújo; } \\
\text { Aníbal Ponce; } \\
\text { Claudio Nei } \\
\text { Nascimento da } \\
\text { Silva. } \\
\text { Dante Henrique } \\
\text { Moura; } \\
\text { Dermeval Saviani; } \\
\text { Gaudêncio } \\
\text { Frigotto: } \\
\text { Maria Ciavatta: } \\
\text { Paulo Reglus } \\
\text { Neves Freire. }\end{array}$ & $\begin{array}{lr}\text { O } & \text { guia } \\
\text { educacional } & \\
\text { contempla } & \\
\text { informações } & \text { e } \\
\text { orientações } & \text { sobre } \\
\text { a organização } \\
\text { didático- } & \\
\text { pedagógica } & \text { e } \\
\text { depoimentos } & \text { de } \\
\text { egressos } & \text { que } \\
\text { relatam } & \text { as } \\
\text { possibilidades } & \text { de } \\
\text { realizar } & \text { um } \\
\text { percurso formativo } \\
\text { com êxito r no } \\
\text { ensino } & \text { Médio } \\
\text { Integrado rro } & \text { do } \\
\text { IFSC-campus } & \\
\text { Florianópolis }\end{array}$ & $\begin{array}{l}\text { O estudo revela as diferentes } \\
\text { estratégias que os estudantes } \\
\text { constroem para permanecer e } \\
\text { ter êxito, apresentando como } \\
\text { resultado alternativas de } \\
\text { adequação da organização } \\
\text { pessoal e acadêmica e de } \\
\text { acesso às ações institucionais } \\
\text { que estão compartilhadas no } \\
\text { guia educacional }\end{array}$ \\
\hline $\begin{array}{|lr|}\text { Permanência r } & \text { e } \\
\text { êxito dos egressos } \\
\text { do PROEJA no } \\
\text { campus } & \\
\text { Sertãozinho r do } \\
\text { IFSP: um resgate }\end{array}$ & $\begin{array}{l}\text { Gestão e } \\
\text { Organizaçã } \\
\text { o do do } \\
\text { Espaço } \\
\text { Pedagógico } \\
\text { em }\end{array}$ & $\begin{array}{l}\text { Quais são os grandes } \\
\text { desafios institucionais } \\
\text { em garantir a } \\
\text { permanência e êxito } \\
\text { dos alunos na } \\
\text { modalidade } \quad \text { de }\end{array}$ & $\begin{array}{l}\text { Dermeval Saviani. } \\
\text { Gaudêncio } \\
\text { Frigotto; } \\
\text { Jaqueline Moll; } \\
\text { Dante Henrique } \\
\text { Moura; }\end{array}$ & $\begin{array}{l}\text { Documentário } \\
\text { pautado no } \\
\text { contexto histórico } \\
\text { em que se deu a } \\
\text { criação do Curso } \\
\text { técnico rem }\end{array}$ & $\begin{array}{l}\text { Como resultado da pesquisa, } \\
\text { há o apontamento para a } \\
\text { existência de múltiplos fatores } \\
\text { que influenciam para o êxito } \\
\text { ou para o fracasso do aluno. } \\
\text { compreender os fatores de }\end{array}$ \\
\hline
\end{tabular}




\begin{tabular}{|c|c|c|c|c|c|}
\hline $\begin{array}{l}\text { histórico } \\
\text { Sertãozinho - SP } \\
\text { (PINTO, 2020) }\end{array}$ & $\begin{array}{l}\text { EPT } \\
\text { Servidora } \\
\text { Pública } \\
\text { (IFSP). }\end{array}$ & $\begin{array}{l}\text { educação de jovens e } \\
\text { adultos (PROEJA)? }\end{array}$ & $\begin{array}{l}\text { Maria Ciavatta; } \\
\text { Marise Nogueira } \\
\text { Ramos. }\end{array}$ & \begin{tabular}{|l|} 
mecânica \\
integrado a ensino \\
médio no campus \\
Sertãozinho, \\
tendo como \\
procedimento \\
metodológico a \\
história oral
\end{tabular} & $\begin{array}{l}\text { permanência e êxito por meio } \\
\text { dos egressos, possibilitou } \\
\text { desvencilhar desses alunos o } \\
\text { estigma do fracasso escolar a } \\
\text { eles incessantemente } \\
\text { relacionado }\end{array}$ \\
\hline $\begin{array}{lr}\text { Evasão escolar em } \\
\text { cursos de educação } \\
\text { profissional } & \text { e } \\
\text { tecnológica } & a \\
\text { distância no } & \text { SENAI } \\
\text { Goiás } & \\
\text { fatores } & \\
\text { intervenientes } & \text { (SÁ } \\
\text { FILHO, 2019) } & \end{array}$ & $\begin{array}{l}\text { Gestão e } \\
\text { Organizaçã } \\
\text { o do } \\
\text { Espaço } \\
\text { Pedagógico } \\
\text { em EPT - } \\
\text { Vínculo: } \\
\text { Celetista, } \\
\text { SENAI/GO. }\end{array}$ & $\begin{array}{l}\text { Como mitigar o } \\
\text { problema de evasão } \\
\text { no SENAI de Goiás? }\end{array}$ & $\begin{array}{l}\text { Anderson George } \\
\text { Rafael Santos; } \\
\text { Dermeval Saviani; } \\
\text { Gaudêncio } \\
\text { Frigotto; } \\
\text { Katia Siqueira de } \\
\text { Freitas; } \\
\text { Onília Cristina de } \\
\text { Souza } \\
\text { Almeida. }\end{array}$ & $\begin{array}{lr}\text { A aplicação de um } \\
\text { projeto técnico- } \\
\text { pedagógico r de } \\
\text { acompanhamento } \\
\text { dos alunos nos } \\
\text { primeiros } 90 \text { dias } \\
\text { de realização do } \\
\text { curso técnico em } \\
\text { Automação } \\
\text { Industrial } \\
\text { realizado rr na } \\
\text { modalidade EaD, } \\
\text { período em que } \\
\text { ocorre } \\
\text { índice maior } \\
\text { desistência }\end{array}$ & $\begin{array}{l}\text { Os resultados demonstram } \\
\text { que os motivos de abandono } \\
\text { estão ligados a três fatores: } \\
\text { fatores individuais, fatores } \\
\text { internos à própria instituição } \\
\text { de ensino e fatores externos. } \\
\text { Destaca-se que a maioria dos } \\
\text { alunos desistem do curso, por } \\
\text { não conseguirem conciliar } \\
\text { trabalho e estudo. Expondo } \\
\text { uma das principais mazelas do } \\
\text { Sistema Educacional } \\
\text { brasileiro. }\end{array}$ \\
\hline 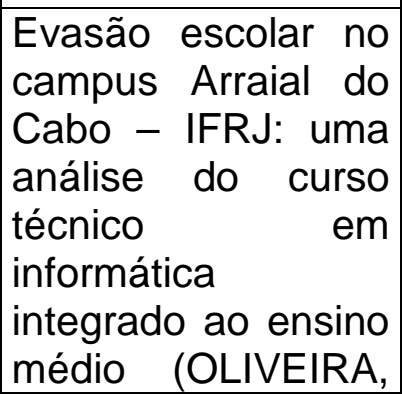 & $\begin{array}{l}\text { Organizaçã } \\
\text { o e } \\
\text { Memórias } \\
\text { de Espaços } \\
\text { Pedagógico } \\
\text { s em EPT - } \\
\text { Não } \\
\text { Informado }\end{array}$ & $\begin{array}{l}\text { Como diminuir a } \\
\text { evasão e contribuir } \\
\text { com a permanência e } \\
\text { êxito escolar na EPT } \\
\text { do Rio de } \\
\text { Janeiro/campus de } \\
\text { Arraial do Cabo/IFRJ- } \\
\text { CAC? }\end{array}$ & $\begin{array}{l}\text { Dermeval Saviani; } \\
\text { Gaudêncio } \\
\text { Frigotto. } \\
\text { Maria Ciavatta; } \\
\text { Marise Nogueira } \\
\text { Ramos. }\end{array}$ & \begin{tabular}{|lr} 
Cartilha & de \\
orientação & sobre \\
evasão &
\end{tabular} & 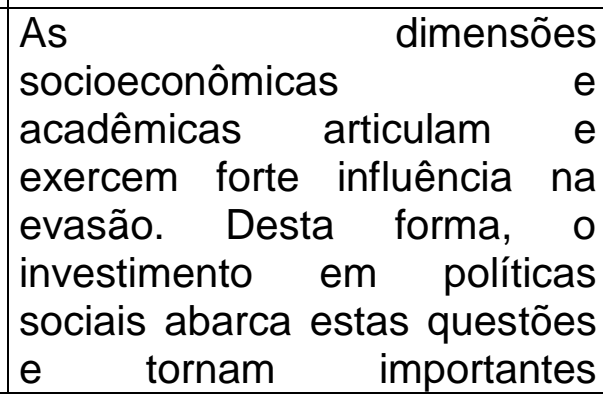 \\
\hline
\end{tabular}




\begin{tabular}{|c|c|c|c|c|c|}
\hline 2019). & & & & & $\begin{array}{l}\text { estratégias para permanência } \\
\text { e êxito. }\end{array}$ \\
\hline $\begin{array}{l}\text { Evasão, retenção e } \\
\text { permanência de } \\
\text { estudantes } \\
\text { indígenas no } \\
\text { campus Guajará- } \\
\text { Mirim do instituto } \\
\text { federal de educação } \\
\text { ciência e tecnologia } \\
\text { de Rondônia - IFRO } \\
\text { (ESTEVÃO, 2021) }\end{array}$ & $\begin{array}{l}\text { Organizaçã } \\
\text { o e } \\
\text { Memórias } \\
\text { de Espaços } \\
\text { pedagógico } \\
\text { S na EPT - } \\
\text { Servidora } \\
\text { Pública } \\
\text { (IFRO) }\end{array}$ & $\begin{array}{l}\text { Como as medidas de } \\
\text { políticas de inclusão } \\
\text { que têm contribuído } \\
\text { para a permanência e } \\
\text { o êxito de alunos } \\
\text { indígenas dos cursos } \\
\text { técnicos integrados ao } \\
\text { ensino médio do } \\
\text { campus? }\end{array}$ & $\begin{array}{l}\text { Maria Aparecida } \\
\text { Bergamaschi; } \\
\text { Marise Nogueira } \\
\text { Ramos. } \\
\text { Vera Maria Ferrão } \\
\text { Candau; } \\
\text { Xênia de Castro } \\
\text { Barbosa. }\end{array}$ & \begin{tabular}{lr} 
Protocolo & de \\
acolhimento & de \\
estudantes & \\
indígenas ao \\
IFRO - campus \\
\multicolumn{2}{|l}{ Guajará-Mirim }
\end{tabular} & $\begin{array}{l}\text { Os resultados do estudo } \\
\text { demonstram que o diálogo } \\
\text { intercultural é essencial na } \\
\text { inclusão educacional indígena } \\
\text { e para uma cultura que } \\
\text { perpassa pela compreensão e } \\
\text { valorização da diversidade e } \\
\text { efetivação de direitos sociais. }\end{array}$ \\
\hline $\begin{array}{l}\text { Evasão escolar no } \\
\text { curso técnico em } \\
\text { agropecuária } \\
\text { integrado ao nível } \\
\text { médio do IFMT - } \\
\text { câmpus r São } \\
\text { Vicente: } \\
\text { proposta de } \\
\text { como instrumento } \\
\text { de apoio aos } \\
\text { trabalhos }\end{array}$ & $\begin{array}{l}\text { Organizaçã } \\
\text { o e e } \\
\text { Memórias } \\
\text { de Espaços } \\
\text { Pedagógico } \\
\text { S na EPT - } \\
\text { Servidora } \\
\text { Pública } \\
\text { (IFMT) }\end{array}$ & $\begin{array}{lr}\text { Como a } & \text { abordagem } \\
\text { preditiva } & \text { pode } \\
\text { contribuir para evitar a } \\
\text { evasão escolar nos } \\
\text { cursos } & \text { técnicos } \\
\text { integrados ao nível } \\
\text { médio? }\end{array}$ & $\begin{array}{l}\text { Dermeval Saviani; } \\
\text { Gaudêncio } \\
\text { Frigotto; Reglus } \\
\text { Paulo Reve Freire. }\end{array}$ & $\begin{array}{lr}\text { Guia de apoio aos } \\
\text { trabalhos } & \text { de } \\
\text { permanência } & \text { e } \\
\text { êxito } & \end{array}$ & $\begin{array}{l}\text { Os resultados apontam que os } \\
\text { principais motivos de evasão } \\
\text { escolar do curso Técnico em } \\
\text { Agropecuária, no ano de } 2018 \text {, } \\
\text { foram as dificuldades de } \\
\text { aprendizagem, o excesso de } \\
\text { disciplinas no curso e os } \\
\text { problemas familiares }\end{array}$ \\
\hline
\end{tabular}




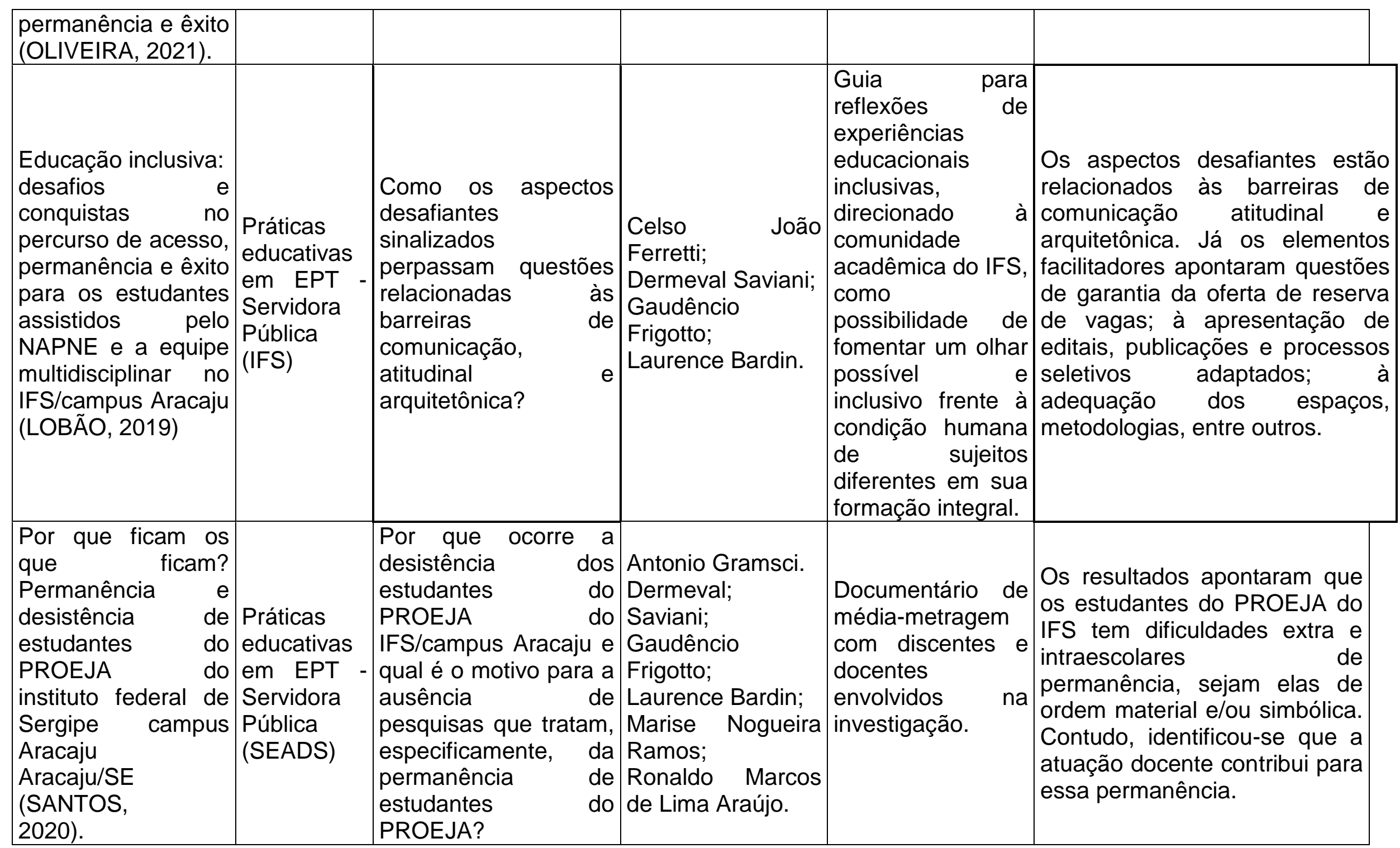




\begin{tabular}{|c|c|c|c|c|c|}
\hline $\begin{array}{l}\text { "combo" da } \\
\text { trajetória da } \\
\text { formação escolar no } \\
\text { IFS: o acesso, a } \\
\text { permanência e o } \\
\text { êxito dos } \\
\text { estudantes negros } \\
\text { cotistas no Ensino } \\
\text { médio integrado do } \\
\text { campus Aracaju } \\
\text { (MENDES, 2019). }\end{array}$ & $\begin{array}{l}\text { Práticas } \\
\text { educativas } \\
\text { em EPT } \\
\text { Servidora } \\
\text { Pública } \\
\text { (IFS) }\end{array}$ & 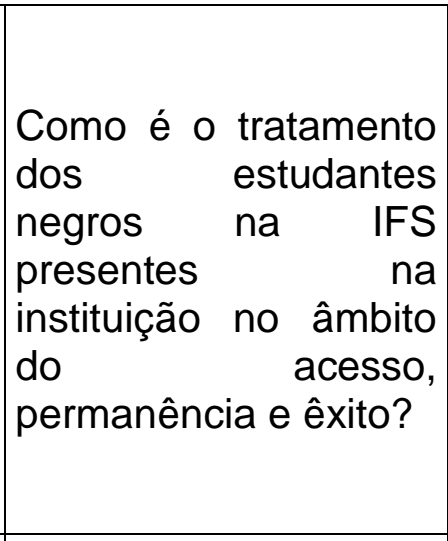 & $\begin{array}{l}\text { Acácia Kuenzer; } \\
\text { Dermeval Saviani. } \\
\text { Gaudêncio } \\
\text { Frigotto; } \\
\text { Karl Marx; } \\
\text { Paulo Reglus } \\
\text { Neves Freire; } \\
\text { Silvio de Almeida. }\end{array}$ & \begin{tabular}{|l} 
Documentário \\
com os discentes \\
envolvidos na \\
pesquisa.
\end{tabular} & $\begin{array}{l}\text { Determina a necessidade de } \\
\text { um maior aprofundamento e } \\
\text { avanço do IFS nas discussões } \\
\text { e ações em torno da questão } \\
\text { étnico-racial, com foco em } \\
\text { tomar a centralidade desse } \\
\text { debate dentro da instituição. }\end{array}$ \\
\hline $\begin{array}{lr}\text { Possibilidades } & \text { de } \\
\text { acesso } & e \\
\text { permanência } & \text { da } \\
\text { pessoa } & \text { com } \\
\text { deficiência } & \text { na } \\
\text { educação } & \\
\text { profissional } & \text { e } \\
\text { tecnológica de nível } \\
\text { médio no IFSUL - } \\
\text { câmpus Sapucaia } \\
\text { do Sul } \\
\text { (SILVA, 2020). }\end{array}$ & $\begin{array}{l}\text { Práticas } \\
\text { educativas } \\
\text { em EPT - } \\
\text { Servidor } \\
\text { (IFPR). }\end{array}$ & $\begin{array}{l}\text { Como é o tratamento } \\
\text { de pessoas com } \\
\text { deficiências r nos } \\
\text { Institutos Federais? }\end{array}$ & $\begin{array}{l}\text { Antonio Gramsci; } \\
\text { Dermeval Saviani; } \\
\text { Gaudêncio } \\
\text { Frigotto; } \\
\text { Maria Ciavatta. } \\
\text { Marise Nogueira } \\
\text { Ramos. }\end{array}$ & \begin{tabular}{|lr} 
Planejamento e a \\
construção de um \\
aplicativo \\
educacional com \\
informações \\
consistentes sobre \\
as r principais \\
deficiências nas na \\
área educacional \\
além r disso \\
contempla r \\
também \\
principais \\
pressupostos das \\
bases conceituais \\
da EPT.
\end{tabular} & $\begin{array}{l}\text { A pesquisa aponta a } \\
\text { importância do Núcleo de } \\
\text { apoio a pessoas com } \\
\text { necessidades específicas, no } \\
\text { processo de inclusão da } \\
\text { pessoa com deficiência dentro } \\
\text { dos Institutos Federais, } \\
\text { evidenciando, diversas } \\
\text { práticas inclusivas, } \\
\text { possibilitando o acesso e } \\
\text { permanência da pessoa com } \\
\text { deficiência no IFSUL. }\end{array}$ \\
\hline
\end{tabular}

Fonte: Elaborado pelos Autores, (2021)

Nota: Dados obtidos no Observatório ProfEPT, sobre dissertações defendidas no programa. A pesquisa foi realizada com a palavra de busca "permanecia" e foi efetivada em $05 / 11 / 2021$. 
O mestrado ProfEPT é organizado em duas linhas de pesquisas: Práticas educativas em EPT e a segunda, Organização e Memórias de Espaços Pedagógicos na EPT. Com a consulta no Observatório ProfEPT, objeto desta pesquisa, percebeuse que $65 \%$ das dissertações foram classificadas pelos seus autores como pertencentes a linha de pesquisa Organização e Memórias de Espaços Pedagógicos na EPT. Portanto, o estudo sobre evasão foi distribuído de forma equilibrada entre ambas as linhas de pesquisas do mestrado. Como apresentado na Figura 1, 80\% dos autores das dissertações são servidores públicos. Nos processos seletivos do programa, metade das vagas são destinadas aos servidores da RFEPT e a outra metade são de ampla concorrência.

FIGURA 1 - Tipo de Vínculo do Mestrando das 20 Dissertações Investigadas

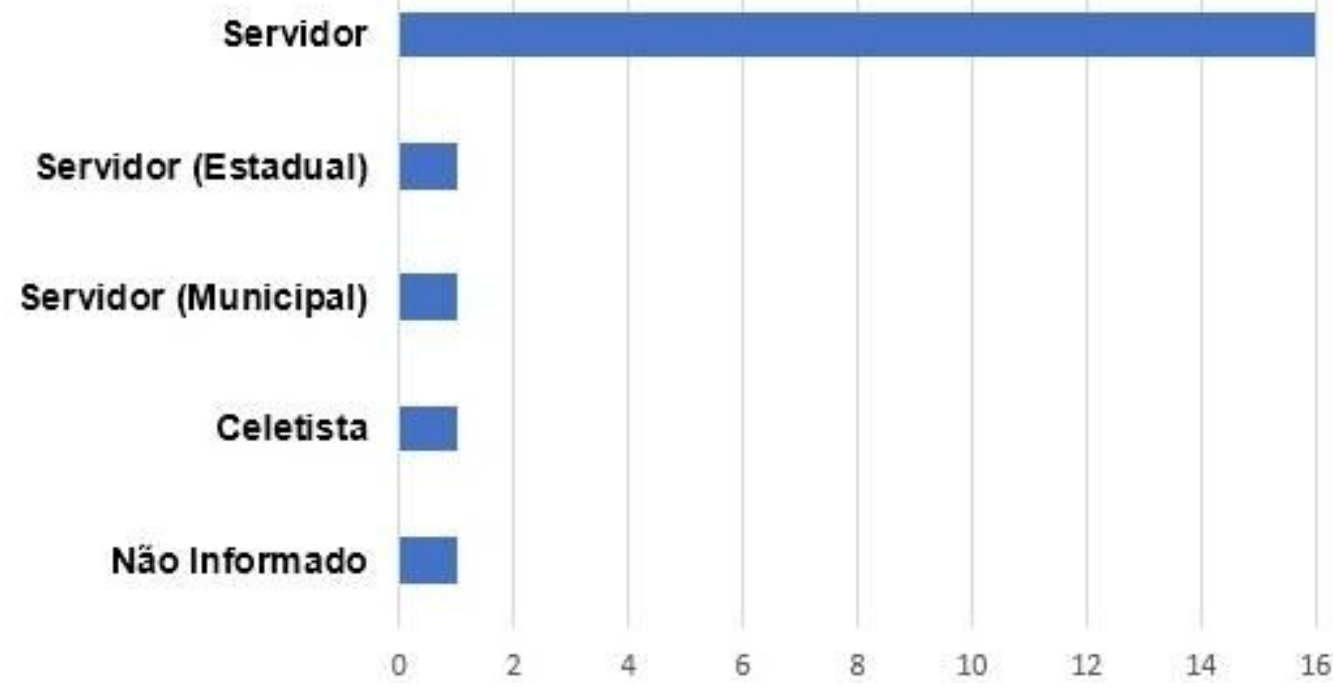

Fonte: Elaborado pelos autores, (2021).

Nota: Dados obtidos no Observatório ProfEPT, sobre dissertações defendidas no programa. A pesquisa foi realizada com a palavra de busca "permanecia" e foi efetivada em $05 / 11 / 2021$.

Dentre os autores das dissertações pesquisadas, $80 \%$ optaram pelo desenvolvimento do produto educacional do tipo guia, como apresentado na Figura 2. É possível concluir que isso tenha ocorrido em função da necessidade de orientação aos servidores da educação pela Comissão de Permanência e Êxito que deve existir nas instituições que compõem a Rede Federal de Educação Profissional e Tecnológica. E o documentário surgiu como elemento de sensibilização destes profissionais acerca do tema. 
FIGURA 2 - Tipologia dos Produtos Educacionais Aplicados e Validados

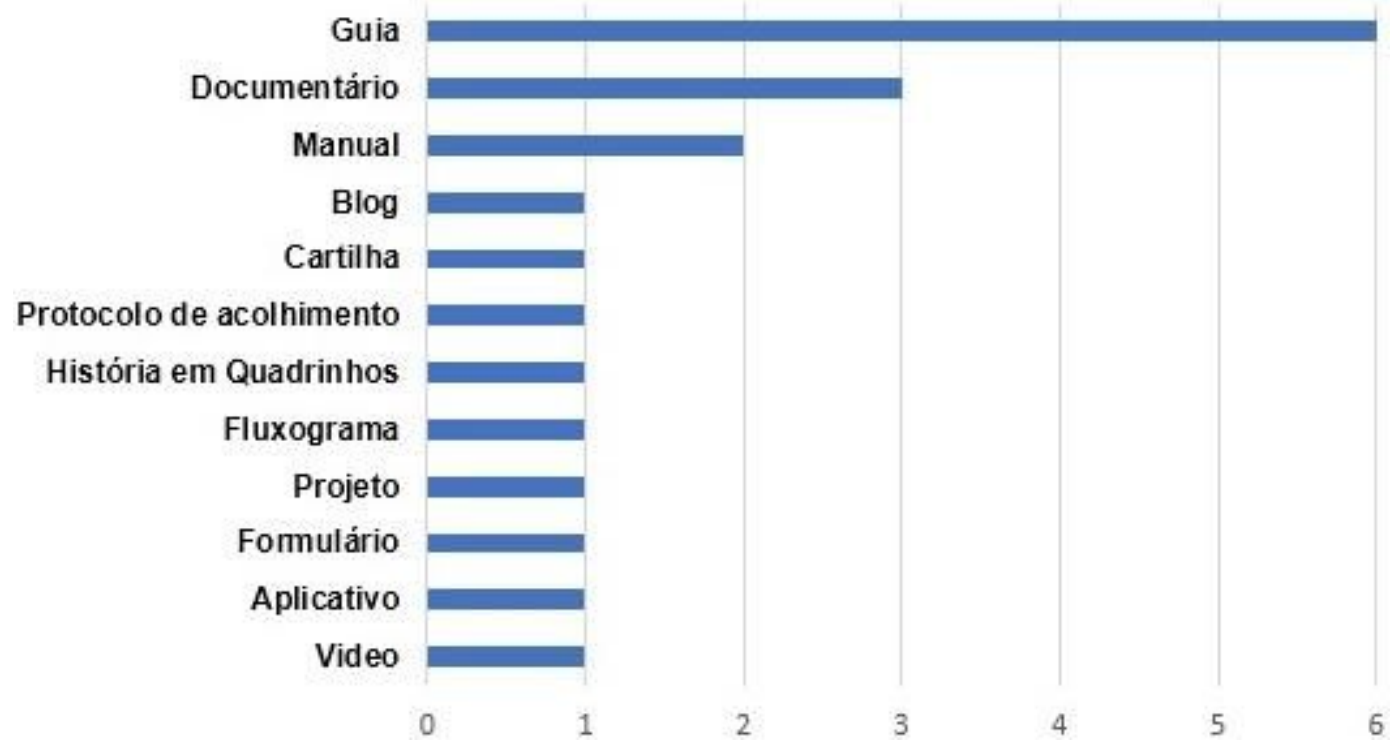

Fonte: Elaborado pelos autores, (2021).

Nota: Dados obtidos no Observatório ProfEPT, sobre dissertações defendidas no programa. A pesquisa foi realizada com a palavra de busca "permanecia" e foi efetivada em $05 / 11 / 2021$.

A avaliação do Quadro 1 permite identificar os autores utilizados nos aportes teóricos das dissertações defendidas no âmbito do ProfEPT. Os 10 autores utilizados em mais dissertações são apresentados na Figura 3. Destaca-se Gaudêncio Frigotto, seguido por Dermeval Saviani, Maria Ciavatta, Marise Nogueira Ramos, Paulo Reglus Neves Freire, Dante Henrique Moura, Acácia Kuenzer e José Carlos Libâneo.

As condições socioeconômicas das famílias influenciam a situação acadêmica do estudante, e contribui para sua permanência ou evasão do sistema escolar. Não é raro famílias em situações financeiras desfavoráveis que retiram suas crianças e adolescentes da escola a fim de que eles desenvolvam trabalhos para contribuírem financeiramente com os outros membros do grupo familiar. Tais situações provocam sérios problemas para o indivíduo, sejam os relacionados com aspectos psicológicos ou com os aspectos profissionais, em função da possível baixa escolaridade (FERREIRA; KUNZE, 2021).

Percebe-se ainda que a motivação é um importante pilar que pode contribuir com a mitigação da evasão escolar, como apresenta Mendes (2013). Figueiredo e Salles (2017) destacam a escolha do curso, fatores escolares, dificuldades pessoais, influência de amigos, oportunidades e desinteresse institucional e/ou governamental como fatores que contribuem para a evasão dos alunos. 
FIGURA 3 - Os oito pesquisadores mais utilizados como aporte teórico das dissertações defendidas no programa ProfEPT, sobre o tema Evasão Escolar, durante o período de janeiro de 2019 a novembro de 2021

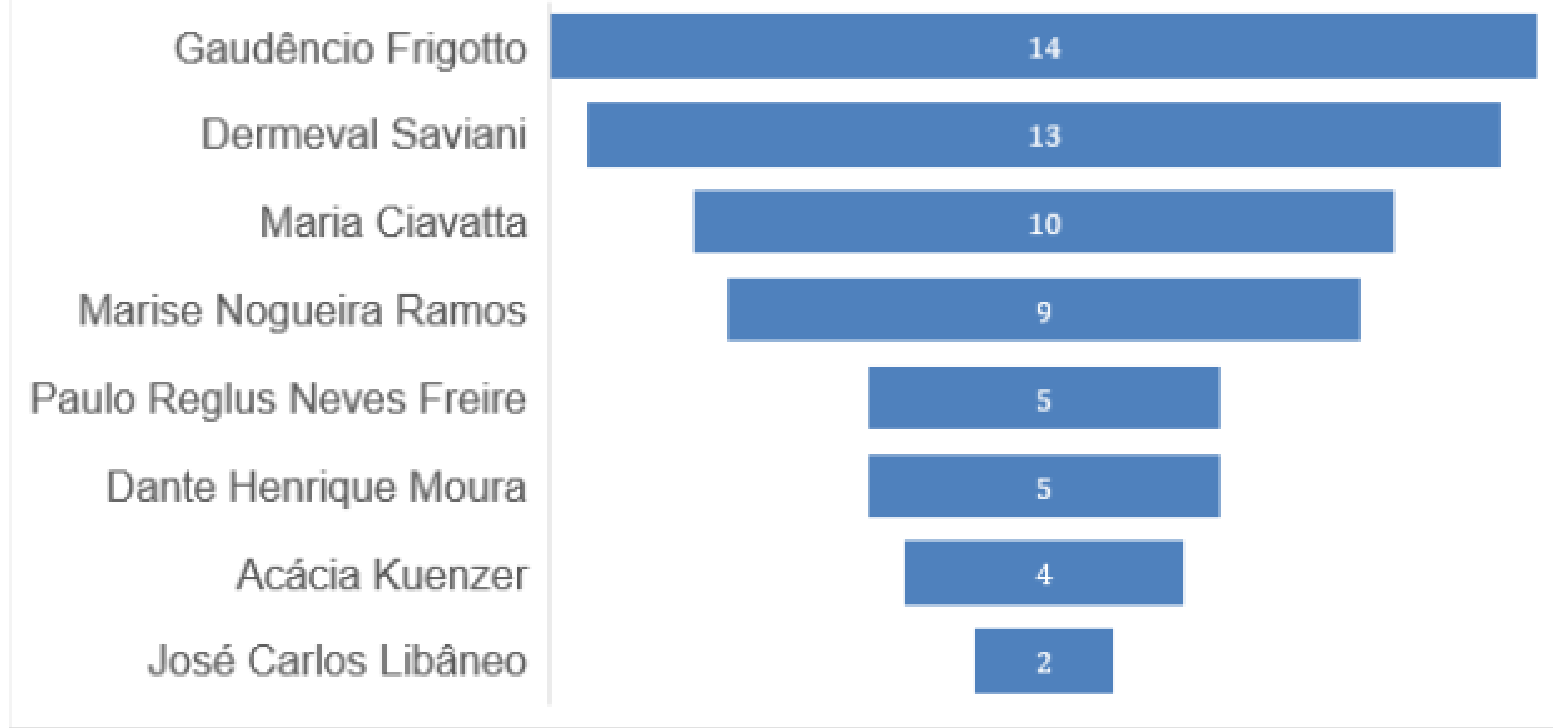

Fonte: Elaborado pelos autores, (2021).

Nota: Dados obtidos no Observatório ProfEPT, sobre dissertações defendidas no programa. A pesquisa foi realizada com a palavra de busca "permanecia" e foi efetivada em $05 / 11 / 2021$.

Ademais, é importante destacar que a legislação vigente imputa a família e ao estado a obrigação de manter os alunos nas escolas, até a completa formação acadêmica, pois é:

dever da família, da sociedade e do Estado assegurar à criança e ao adolescente, com absoluta prioridade, o direito à vida, à saúde, à alimentação, à educação, ao lazer, à profissionalização, à cultura, à dignidade, ao respeito, à liberdade e à convivência familiar e comunitária, além de colocá-los a salvo de toda forma de negligência, discriminação, exploração, violência, crueldade e opressão (BRASIL, 1988, art. 227).

De acordo com a Plataforma Nilo Peçanha (PNP), sistema que organiza e publica estatísticas acadêmicas e administrativas da RFEPT, a taxa de evasão nos cursos técnicos, em 2021, foi de $14,44 \%$, como apresentado na Figura 4. Dessa forma essa problemática deve ser enfrentada como prioridade, devido a esses números serem desanimadores. Sousa (2020) descreve que nesta perspectiva, o combate à evasão precisa estar articulado com a análise de outros fenômenos educativos, especialmente a retenção, devendo subordinar-se à compreensão do sucesso e do fracasso da aprendizagem escolar. 
FIGURA 4 - Situação de Matrícula dos Alunos da RFEP do ano base 2020

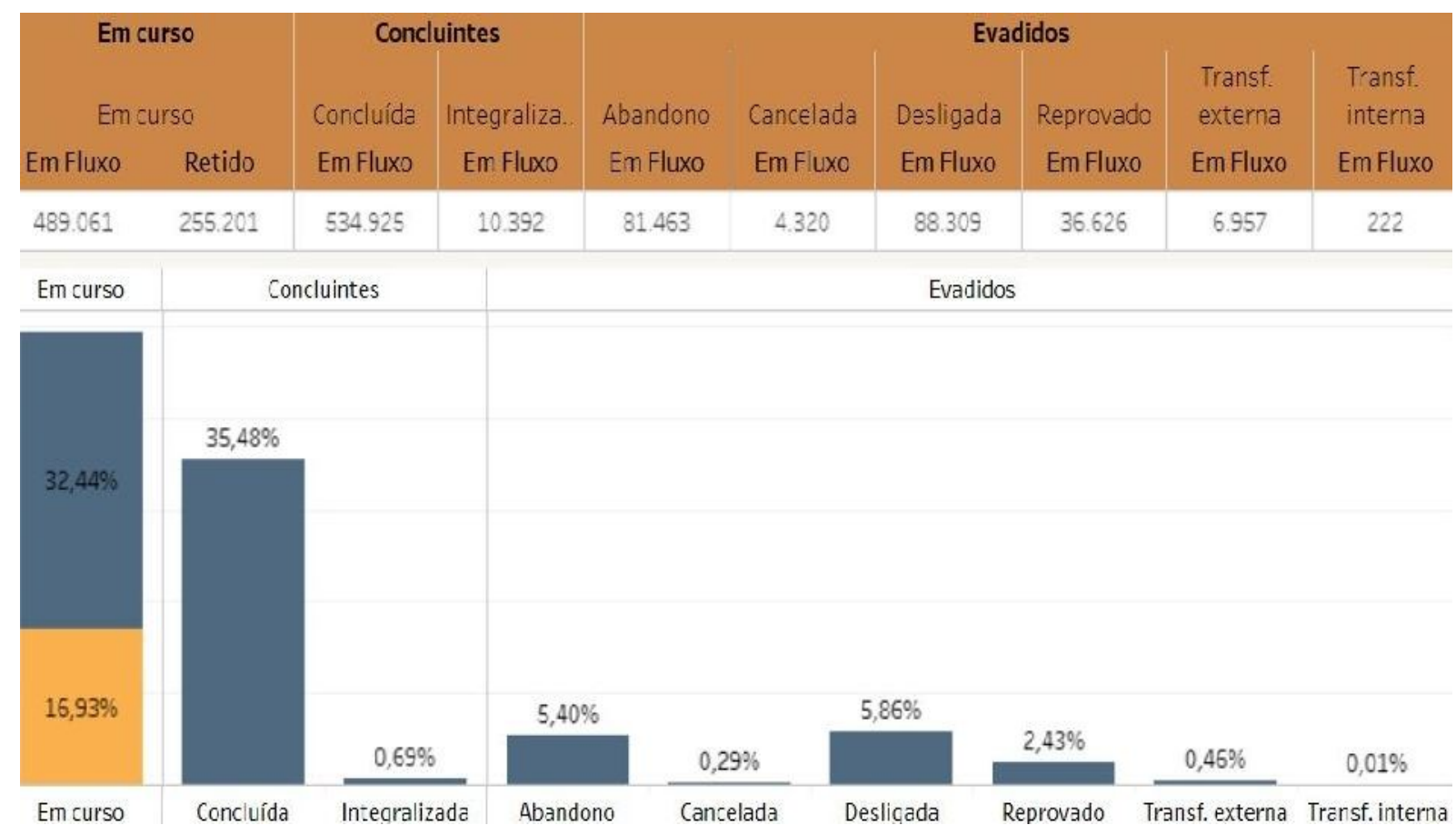

Fonte: Plataforma Nilo Peçanha, (2021).

Nota: Dados obtidos na Plataforma Nilo Peçanha (BRASIL, 2018), consultado em 12/11/2021.

Destaca-se as importantes contribuições dos autores das dissertações apresentadas na mitigação da evasão escolar. Cada dissertação apresenta um produto educacional que foi desenvolvido e aplicado em uma instituição, cuja validação ocorreu pelos membros que compuseram a banca do mestrado.

De acordo com o Quadro 1, os autores das dissertações pesquisadas relacionam alguns fatores entre eles: as estruturas físicas da instituição; falta de identificação com o curso; carga horária do curso elevada; dificuldade de conciliar trabalho e estudo; fatores socioeconômicos, dificuldades de aprendizagem; problemas familiares.

\section{CONCLUSÕES}

A avaliação dos motivos que geram a evasão estudantil são temáticas relevantes que devem ser trabalhadas no âmbito escolar, por todos os profissionais da educação, e no seio familiar, por todos os membros da família. De forma a garantir o acesso à educação a todas as crianças, adolescentes e adultos.

O desenvolvimento da pesquisa relatada neste artigo permitiu identificar iniciativas de combate à evasão escolar com o emprego de produtos educacionais desenvolvidos na Rede Federal de Educação Profissional e Tecnológica, no âmbito do Programa de Mestrado ProfEPT. Estes produtos podem ser utilizados nas demais instituições.

A avaliação das dissertações apresentadas no Quadro 1 permitem concluir que existem ações que contribuem com a mitigação da evasão escolar. Os autores destacam: a boa relação professor aluno; a atuação integrada da equipe multidisciplinar da escola; o despertar do sentimento de pertencimento e identidade no ambiente escolar do aluno; a área do curso alinhada à demanda profissional 
local; a boa didática do docente em sua prática profissional; o reconhecimento e o protagonismo do aluno; a implantação e uso da monitoria; a existência do diálogo intercultura; e a atuação efetiva do núcleo de apoio para os alunos com necessidades específicas.

Foi possível identificar os principais autores que contribuem com a temática estudada, este aporte teórico é fundamental para compreender a situação atual dos estudantes, seus familiares, e a instituição acadêmica. Os pesquisadores mais utilizados constituem parte do grupo de autores das obras fundamentais das Bases Conceituais do Programa, portanto, é possível concluir que existe o diálogo entre os textos dos mestres formados no programa com as bases teóricas que sustentam o mestrado. Finalmente, é possível concluir que as pesquisas relatadas podem contribuir com o combate à evasão escolar.

Espera-se que este artigo possa contribuir com os profissionais da educação para combater a evasão, com o aprimoramento de suas práticas profissionais nas instituições em que atuam.

\section{REFERÊNCIAS}

ANDRADE, T. L.,ALMEIDA, C. M.M.; BABOSA, J.L.V.; RIGO, S.J. Metodologias Ativas integradas a um Sistema de Recomendação e Mineração de Dados Educacionais para a mitigação de evasão em EaD. In: Anais do XXXII Simpósio Brasileiro de Informática na Educação. SBC, 2021. p. 824-835.

BARBOSA, R. F. Evasão e reprovação no ensino médio integrado do CEFETMG campus Leopoldina: uma proposta de manual para a comissão de permanência e êxito. 2019. Dissertação (Mestrado Profissional em Rede Nacional de Educação Profissional e Tecnológica) - Instituto Federal de Educação, Ciência e Tecnologia de Minas Gerais, Rio Pomba, 2019. Disponível em: $<$ https://sucupira.capes.gov.br/sucupira/public/consultas/coleta/trabalhoConclusao/vi ewTrabalhoConclusao.jsf?popup=true\&id_trabalho=7893708>. Acesso em: 03 de out. de 2021.

BRASIL. Ministério da Educação. Secretaria de Educação Profissional e Tecnológica. PLATAFORMA NILO PEÇANHA. Brasília: SETEC, 2018. Disponível em: <http://plataformanilopecanha.mec.gov.br/2021.html>. Acesso 28 de nov. 2021.

BRASIL. Ministério da Educação. SISTEMA E-MEC: EDUCAÇÃO SUPERIOR. Brasília: MEC, 2017. Disponível em: <https://emec.mec.gov.br/emec/educacaosuperior/cursos>. Acesso em: 28 nov. 2021.

BRASIL. Constituição da República Federativa do Brasil. Artigo 227. Brasília-DF: Senado, $1988 . \quad$ Disponível em: <http://www.planalto.gov.br/ccivil_03/constituicao/constituicao.htm>. Acesso em: 03 de out. 2021.

BRASIL. Tribunal de Contas da União. Acórdão no 506/2013 - TCU - Plenário, de 13 de março de 2013. Auditoria Operacional. Fiscalização de orientação centralizada. Rede federal de educação profissional. Necessidade de aprimoramentos nas atuações relacionadas à evasão escolar, à interação com os arranjos produtivos locais e ao apoio à inserção profissional dos alunos. Carência de professores e de profissionais de laboratório. Ausência de instalações físicas 
adequadas em alguns institutos federais. Determinação. Comunicações. Brasília: Tribunal de Contas da União, [2013]. Disponível em: $<$ https://pesquisa.apps.tcu.gov.br/\#/documento/acórdão completo/*/KEY\%253AACORDAO-COMPLETO 1250021/DTRELEVANCIA\%2520desc/0/sinonimos\%253Dfalse >. Acesso em: 02 out. de 2021.

CARMO, G. T. do. (org.). Dos estudos da evasão para os da permanência e do êxito escolar: um giro paradigmático. Campos dos Goytacazes: Brasil Multicultural, 2018. $136 \mathrm{p}$.

COSTA, D. P. O. Educação profissional e tecnológica: avaliação do ensino como instrumento de gestão para a permanência escolar. 2020. Dissertação (Mestrado Profissional em Rede Nacional de Educação Profissional e Tecnológica) Instituto Federal de Educação, Ciência e Tecnologia do Pernambuco, Olinda, 2020. Disponível

em: <https://sucupira.capes.gov.br//sucupira/public/consultas/coleta/trabalhoConclusao/vi ewTrabalhoConclusao.jsf?popup=true\&id_trabalho=9167252>. Acesso em: 01 de out. de 2021.

COSTA, E. F. Descortinando a evasão escolar: o caso do Instituto Federal de Pernambuco-Campus Vitória de Santo Antão. 2018. Dissertação de Mestrado. Universidade Federal de Pernambuco.

ESTEVÃO, F. L. B. S. Evasão, Retenção e Permanência de Estudantes Indígenas no Campus Guajará-Mirim do instituto federal de educação ciência e tecnologia de Rondônia - IFRO. 2021. Dissertação (Mestrado Profissional em Rede Nacional de Educação Profissional e Tecnológica) - Instituto Federal de Educação, Ciência e Tecnologia de Rondônia, Porto Velho, 2021. Disponível em: < https://educapes.capes.gov.br/handle/capes/586994>. Acesso em: 01 de out. de 2021.

FERREIRA, E. T., KUNZE, N.C. Desenvolvimento de rede neural para análise e tomadas de decisões acerca da evasão escolar no IFMT. In: Nilce Vieira Campos Ferreira; Neil Franco; Paulo Sérgio Dutra. (Org.). História e Historiografia da Educação no Centro-Oeste e Norte Brasileiros: entre pesquisas, formação docente e práticas educativas. 1 ed. Cáceres: Editora Unemat, 2021, v. 1, p. 172-184. Disponível em: <http://portal.unemat.br/?pg=site\&i=editora\&m=cadastros-deobras\&c=historia-e-historiografia-da-educacao-no-centro-oeste-e-norte-brasileiroentre-pesquisas-formacao-docente-e-praticas-educativas-impresso>. Acesso em: 01 de out. de 2021.

FIGUEIREDO, N. G. S., SALLES, D. M. R. Educação Profissional e evasão escolar em contexto: motivos e reflexões. Ensaio: Avaliação e Políticas Públicas em Educação [online]. 2017, v. 25, n. 95, pp. 356-392. Disponível em: <https://doi.org/10.1590/S0104-40362017002500397>. doi: 10.1590/S010440362017002500397. Acesso em: 13 de nov. 2021.

GARCIA, F. C. Fatores da (não) permanência e êxito no instituto federal de Santa Catarina campus Tubarão na voz de alunos concluintes e evadidos. 
2020. Dissertação (Mestrado Profissional em Rede Nacional de Educação Profissional e Tecnológica) - Instituto Federal de Educação, Ciência e Tecnologia de Goiás, Morrinhos, 2020.2 Disponível em: $<$ https://sucupira.capes.gov.br/sucupira/public/consultas/coleta/trabalhoConclusao/vi ewTrabalhoConclusao.jsf?popup=true\&id_trabalho=9302186>. Acesso em: $01 \mathrm{de}$ out. de 2021.

LOBÃO, F. O. Educação Inclusiva: desafios e conquistas no percurso de acesso, permanência e êxito para os estudantes assistidos pelo Napne e a equipe multidisciplinar no IFS/campus Aracaju. 2019. Dissertação (Mestrado Profissional em Rede Nacional de Educação Profissional e Tecnológica) - Instituto Federal de Educação, Ciência e Tecnologia do Sergipe, Aracaju, 2020. Disponível em:

<https://sucupira.capes.gov.br/sucupira/public/consultas/coleta/trabalhoConclusao/vi ewTrabalhoConclusao.jsf?popup=true\&id_trabalho=7902272 >. Acesso em: $01 \mathrm{de}$ out. de 2021.

LUCENA, M. B. Desafios da permanência do estudante-trabalhador no IF Sudeste MG- campus Barbacena: um estudo de caso nos cursos subsequentes. 2020. Dissertação (Mestrado Profissional em Rede Nacional de Educação Profissional e Tecnológica) - Instituto Federal de Educação, Ciência e Tecnologia de Minas Gerais, Rio Pomba, 2020. Disponível em: <https://sucupira.capes.gov.br/sucupira/public/consultas/coleta/trabalhoConclusao/vi ewTrabalhoConclusao.jsf?popup=true\&id_trabalho=9924615>. Acesso em: 01 de out. de 2021.

MARCONI, M. A., LAKATOS, E. M. Fundamentos de metodologia científica. 8. ed.-São Paulo: Atlas, 2017.

MENDES, M. S. Da inclusão à evasão escolar: o papel da motivação no ensino médio. Estudos de Psicologia (Campinas). 2013, v. 30, n. 2, pp. 261-265. Disponível em: <https://www.scielo.br/j/estpsi/a/Pg4SnYsQ5gzWFd688gD4c8b/?lang=pt\#. ISSN 1982-0275 >. Acesso em: 01 de out. de 2021.

MENDES, R. O. O "Combo" da Trajetória da Formação Escolar no IFS: o acesso, a permanência e o êxito dos estudantes negros cotistas no ensino médio integrado do campus Aracaju. 2019. Dissertação (Mestrado Profissional em Rede Nacional de Educação Profissional e Tecnológica) - Instituto Federal de Educação, Ciência e Tecnologia do Sergipe, Aracaju, 2019. Disponível em: $<$ https://sucupira.capes.gov.br/sucupira/public/consultas/coleta/trabalhoConclusao/vi ewTrabalhoConclusao.jsf?popup=true\&id_trabalho=7766579>. Acesso em: 02 de out. de 201.

OLIVEIRA, P. F. Evasão escolar no curso técnico em agropecuária integrado ao nível médio do IFMT - campus São Vicente: uma proposta de guia como instrumento de apoio aos trabalhos de permanência e êxito. 2021. Dissertação (Mestrado Profissional em Rede Nacional de Educação Profissional e Tecnológica) Instituto Federal de Educação, Ciência e Tecnologia do Mato Grosso, Cuiabá, 2021. Disponível em: <https://sucupira.capes.gov.br/sucupira/public/consultas/coleta/trabalhoConclusao/vi 
ewTrabalhoConclusao.jsf?popup=true\&id_trabalho=10727437>. Acesso em: 01 de out. de 2021.

OLIVEIRA, R. E. Evasão escolar no Campus Arraial do Cabo - IFRJ: uma análise do curso técnico em informática integrado ao ensino médio. 2019. Dissertação (Mestrado Profissional em Rede Nacional de Educação Profissional e Tecnológica) - Instituto Federal de Educação, Ciência e Tecnologia do Rio de Janeiro, C. G. 2019. Disponível em: <https://portal1.iff.edu.br/pesquisa-einovacao/pos-graduacao-stricto-sensu/mestrado-profissional-em-educacaoprofissional-e-tecnologica/dissertacoes-

1/dissertacao_ronaldo_efigenio_de_oliveira.pdf/view>. Acesso em: 02 de out. de 2021.

PINTO, K. P. A. Permanência e êxito dos egressos do PROEJA no Campus Sertãozinho do IFSP: um resgate histórico. 2020. Dissertação (Mestrado Profissional em Rede Nacional de Educação Profissional e Tecnológica) - Instituto Federal de Educação, Ciência e Tecnologia de São Paulo, Sertãozinho, 2020. Disponível em: <https://sucupira.capes.gov.br/sucupira/public/consultas/coleta/trabalhoConclusao/vi ewTrabalhoConclusao.xhtml?popup=true\&id_trabalho=10796241>. Acesso em: 02 de out. de 2021.

RAMOS, M. Ensino médio integrado: ciência, trabalho e cultura na relação entre educação profissional e educação básica. Educação profissional e tecnológica no Brasil contemporâneo: desafios, tensões e possibilidades. Porto Alegre: Artmed, p. $42-57,2010$.

RIBEIRO, E. M. Guia educacional sobre os fatores de permanência e êxito dos alunos egressos da rede pública do ensino fundamental no ensino médio integrado do IFSC - Campus Florianópolis. 2020. Dissertação (Mestrado Profissional em Rede Nacional de Educação Profissional e Tecnológica) - Instituto Federal de Educação, Ciência e Tecnologia de Santa Catariana, Florianópolis, 2020. Disponível em: <https://sucupira.capes.gov.br/sucupira/public/consultas/coleta/trabalhoConclusao/vi ewTrabalhoConclusao.jsf?popup=true\&id_trabalho=9961753>. Acesso em: 01 de out. de 2021.

ROSALES, G. F. Evasão e permanência em educação profissional e tecnológica: um estudo a partir dos cursos técnicos integrados do IFSUL campus Camaquã. 2019. Dissertação (Mestrado Profissional em Rede Nacional de Educação Profissional e Tecnológica) - Instituto Federal de Educação, Ciência e Tecnologia do Rio Grande do Sul, Charqueadas, 2019. Disponível em: <https://sucupira.capes.gov.br/sucupira/public/consultas/coleta/trabalhoConclusao/vi ewTrabalhoConclusao.jsf?popup=true\&id_trabalho=7837322>. Acesso em: 01 de out. de 2021.

SÁ FILHO, P. Evasão escolar em cursos de Educação profissional e tecnológica a distância no Senai Goiás. 2019. Dissertação (Mestrado Profissional em Rede Nacional de Educação Profissional e Tecnológica) - Instituto Federal de Educação, Ciência e Tecnologia de Goiás, Morrinhos, 2019. Disponível em: 
$<$ https://repositorio.ifgoiano.edu.br/handle/prefix/428>. Acesso em: 01 de out. de 2021.

SÁ, L. S. A. Atividades e ações de extensão no IFMS: interfaces com a permanência e êxito dos estudantes. 2020. Dissertação (Mestrado Profissional em Rede Nacional de Educação Profissional e Tecnológica) - Instituto Federal de Educação, Ciência e Tecnologia do Mato Grosso do Sul, Campo Grande, 2020. Disponível em: <https://sucupira.capes.gov.br/sucupira/public/consultas/coleta/trabalhoConclusao/vi ewTrabalhoConclusao.jsf?popup=true\&id_trabalho=9939390>. Acesso em: 02 de out. de 2021.

SANTOS, J. Por que ficam os que ficam? Permanência e desistência de estudantes do PROEJA do instituto federal de Sergipe campus Aracaju. 2020. Dissertação (Mestrado Profissional em Rede Nacional de Educação Profissional e Tecnológica) - Instituto Federal de Educação, Ciência e Tecnologia do Sergipe, Aracaju, 2020.

Disponível em:<https://sucupira.capes.gov.br/sucupira/public/consultas/coleta/trabalhoConclusa o/viewTrabalhoConclusao.jsf?popup=true\&id_trabalho=9989617 >. Acesso em: $01 \mathrm{de}$ out. de 201.

SCHARGEL, F. P., SMINK, J. Estratégias para auxiliar o problema de evasão escolar. Rio de Janeiro: Dunya, v. 282, 2002.

SILVA, A. S. J. Possibilidades de acesso e permanência da pessoa com deficiência na educação profissional e tecnológica de nível médio no IFSUL campus sapucaia do sul. 2020. Dissertação (Mestrado Profissional em Rede Nacional de Educação Profissional e Tecnológica) - Instituto Federal de Educação, Ciência e Tecnologia do Rio Grande do Sul, Charqueadas, 2020. Disponível em: <https://sucupira.capes.gov.br/sucupira/public/consultas/coleta/trabalhoConclusao/vi ewTrabalhoConclusao.xhtml?popup=true\&id_trabalho=9280847>. Acesso em: 02 de out. de 201.

SILVA, D. T. S. Um estudo sobre enunciados que permeiam a permanência e a não permanência de alunos no curso de licenciatura em matemática da UFRGS. 2020.

SILVA, E. V. Acesso e permanência no ensino superior: enfoque de classe. 2019. Dissertação (Mestrado Profissional em Rede Nacional de Educação Profissional e Tecnológica) - Instituto Federal de Educação, Ciência e Tecnologia do Ceará, Fortaleza, 2019. Disponível em: <https://sucupira.capes.gov.br/sucupira/public/consultas/coleta/trabalhoConclusao/vi ewTrabalhoConclusao.jsf?popup=true\&id_trabalho=7633872>. Acesso em: 01 de out. de 201.

SOUSA, C. M. A eficiência da monitoria nos cursos técnicos integrados ao ensino médio do instituto federal goiano - campus ceres: o processo de ensino aprendizagem, permanência e êxito escolar. 2019. Dissertação (Mestrado Profissional em Rede Nacional de Educação Profissional e Tecnológica) - Instituto Federal de Educação, Ciência e Tecnologia de Goiás, Morrinhos, 2019. Disponível 
em: <https://repositorio.ifgoiano.edu.br/handle/prefix/581>. Acesso em: 02 de out. de 2021.

SOUSA, M. G. N. Evasão ou permanência na educação profissional tecnológica? um estudo de caso no IFSUL-Rio-Grandense - campus Santana do Livramento. 2020. Dissertação (Mestrado Profissional em Rede Nacional de Educação Profissional e Tecnológica) - Instituto Federal de Educação, Ciência e Tecnologia do Rio Grande do Sul, Porto Alegre, 2020. Disponível em: $<$ https://sucupira.capes.gov.br/sucupira/public/consultas/coleta/trabalhoConclusao/vi ewTrabalhoConclusao.jsf?popup=true\&id_trabalho=9495278>. Acesso em: 02 de out. de 2021.

TAQUETTE, S. R., BORGES, L. Pesquisa qualitativa para todos. Editora Vozes, 2021.

VICENTE, C. C. Conhecendo o curso técnico em metalurgia do IFMG - campus ouro preto: reconstrução histórica do curso como ação motivacional para permanência e êxito discente. 2019. Dissertação (Mestrado Profissional em Rede Nacional de Educação Profissional e Tecnológica) - Instituto Federal de Educação, Ciência e Tecnologia de Minas Gerais, Rio Pomba, 2019. Disponível em: $<$ https://sucupira.capes.gov.br/sucupira/public/consultas/coleta/trabalhoConclusao/vi ewTrabalhoConclusao.jsf?popup=true\&id_trabalho=8748843>. Acesso em: 02 de out. de 2021. 